\title{
Effect of Nonhydrostatic Stress on Crystal Growth Kinetics
}

\section{Citation}

Aziz, Michael J., Paul C. Sabin, and Guo-Quan Lu. 1991. Effect of nonhydrostatic stress on crystal growth kinetics. Materials Research Society Symposia Proceedings 202, 567-572.

\section{Published Version}

http://www.mrs.org/s_mrs/sec.asp?CID=1727\&DID=38980

\section{Permanent link}

http://nrs.harvard.edu/urn-3:HUL.InstRepos:3645197

\section{Terms of Use}

This article was downloaded from Harvard University's DASH repository, and is made available under the terms and conditions applicable to Other Posted Material, as set forth at http:// nrs.harvard.edu/urn-3:HUL.InstRepos:dash.current.terms-of-use\#LAA

\section{Share Your Story}

The Harvard community has made this article openly available.

Please share how this access benefits you. Submit a story.

Accessibility 
FFFCT OF NONHYDROSTATIC STRESS ON CRYSTAL GROWTH KINETICS

Michael J. Aziz, Paul C. Sabin, and Guo-Quan Lua), Division of Applied Sciences, Harvard University, Cambridge MA 02138

\section{ABSTRACT}

The effect of nonhydrostatic stresses on the solid phase epitaxial growth rate of crystalline Tic0) into self-implanted amorphous surface layers has been measured. Uniaxial stresses of Sip 100 into self up to $6 \mathrm{kbar}(0.6 \mathrm{GPa})$ were attained by ben temperature too low for plastic deformation to relieve the stress the tensile side was greater than for solid phase epitaxial growth to proceed. The growth rate on the tensile side was greater than that on the compressive side of the wafer, in marked contrast to the enhancement observed from hydrostatic pressure. The phenomenology of an "activation strain", the nonhydrostatic analoge of the activation volume, has been developed to characterize the results. Combined with the measurement of the activation volume, the measurement reported here permits us to characterize to tirst order the entire activation state the thansition state for this process is "short and fat", phase epitaxy of Si(100). We consion in the two in-plane directions that is, the fluctuation to the transiton sta and a contraction in the direction normal to the surface large enough to make the overall volume change negative. The symmetry of the measured activation strain tensor is inconsistent with

bulk point defect mechanisms for solid phase epitaxy. The relevance
formalism to heteroepitaxy and vapor phase epitaxy is discussed.

\section{INTRODUCTION}

Nonhydrostatic stresses during crystal growth typically occur during strained-laye heteroepitaxy [1-3] or any other epitaxial growth process involving composition discontinuities heteropilaxy 1 . 3 ) or gradients. The effect of research [4-7], here we adres ic a effect of pressure on the kinetic rate constants for crystal grow proved elusive. This is due in part measurement of the effect of nonhydrostatic stress states has proved elusive. This is due in to the difficulty of imposing a controlled amount of nonhydrostatic stress without having
partially relieved and rendered, on a fine scale, non-uniform by dislocation injection.

In a study of the effect of pressure on quartz growth, Fratello et al. found evidence suggesting that nonhydrostatic stresses were even more effective in enhancing the growth than was pressure [4], but the we re of crystalline $\mathrm{Si}$ (c-Si) into self-implantation-amorphized Si (ai) the effect of Si (a-Si) overlays is also enhanced by nonhydrostatic stress on this rate, developed a theory for and used the results to rule out a class of atomistic models for the solid phase epitaxy process $[14,15]$. The measurement was accomplished by elastically bending $\mathrm{Si}$ wafers over fused quase rods at a temperature too low for plastic deformation to occur but high enough for solid phase epitaxial growth to proceed at measurable rates. The difference between the growth rates on the as the stress varied along the length of the wafer.

\section{EXPERIMENT}

Si (100) wafers (p-type, $1 "$ diam., $1 \Omega$-cm, $0.033^{\prime \prime}$ thick, polished on both sides) were implanted on both sides at $77 \mathrm{~K}$ with ${ }^{30} \mathrm{Si}^{+}\left(60 \mathrm{keV}, 1 \times 10^{15} / \mathrm{cm}^{2},<1.0 \mu \mathrm{A} / \mathrm{cm}^{2}\right.$, followed by surface layers 2

were diced into bars $>20 \mathrm{~mm}$ long in the [011] direction, by $5 \mathrm{~mm}$ wide. 
Stress was imposed in air with a three-point bending system, depicted in Fig. 1. The sample rested on a pair of parallel fused quartz rods spaced $20 \mathrm{~mm}$ apart. A third fused quartz rod made contact with the sample from above. Weights were added to control the stress applied to the

Fig. I. Schematic cross section of three. point bending apparatus for annealing wafers under nonhydrostatic stress. S: sample, cross-hatched areas correspond to amorphou Si, C: calibration sample; $Q:$ fused quartz support rods, $P$. brass plate, $G$ gudide posts weights; $L$ : lid.

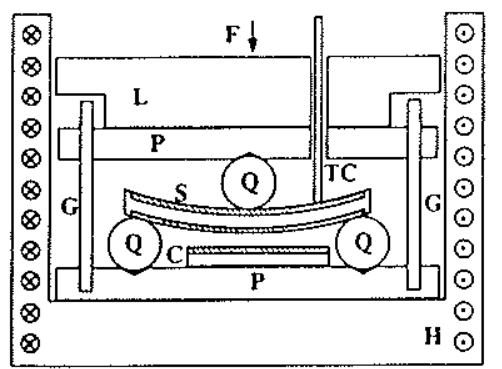

sample. An unstressed "calibration sample", which had only the top surface implanted, lay below the experimental sample; it served to calibrate temperatures and/or gradients.

The apparatus was pre-heated in the fumace to $\sim 560^{\circ} \mathrm{C}$. The top piece of the apparatus was removed and the sample and "calibration sample" were inserted quickly; this resulted in a temperature drop of slightly more than $20^{\circ} \mathrm{C}$. Subsequently the temperature was stabilized at $540 \pm 2^{\circ} \mathrm{C}$ within 8 minutes. Concurrently, the appropriate weight was completely added within 4 minutes. Typical anneal durations were $60-90 \mathrm{~min}$. The sample was removed from the fumace as quickly as possible after the load had been removed, while it was still hot. After annealing, the thickness of the remaining a-Si layer was determined by Rutherford Backscattering Spectrometry and ion channeling [16] using $2 \mathrm{MeV}^{4} \mathrm{He}^{+}$. The beam spot diameter was $-1.5 \mathrm{~mm}$.

The stress state of the bar-shaped wafer in bending can be approximated as a uniaxial stress which varies linearly through the wafer thickness, with one side under compression and the other side under an equal amount of tension. Under the three-point bending load, the stress in the wafer also varies linearly from the single loading point at the center silica rod to the points of contact of the two supporting end rods. The magnitude of the stress is maximum on the wafer surface at the central loading point, and is zero at the point of contact of the two supporting end rods. At the wafer surface,

$$
\sigma_{11}(x)= \pm \frac{|x|-L / 2}{b h^{2} / 3} F,
$$

where $\sigma_{i j}$ is the stress tensor, $\mathrm{x}$ is the distance from the point of contact of the center rod, $\mathrm{L}$ is the length of the bar between the supporting end rods, $F$ is the loading force on the bar, $b$ is the width, and $h$ is the thickness of the bar. All other $\sigma_{i j}$ are zero in this approximation. The stress calculated from eq. (1) exists in the crystal at the crystal/amorphous interface. There is no stress in the bulk of the a-Si due to very rapid stress relief by viscous flow [17]. This was

demonstrated by cooling down a sample while still loaded, after only a small amount of crystal growth. The sample retained its currature when the load was removed. Upon annealing after the removal of the load, the sample straightened out again. Furthermore, that all samples stressed to $>5 \mathrm{kbar}$ during annealing broke into several pieces during careful removal of the load may be a consequence of flow.

The average growth rate for a sample whose maximum stress was $\sigma_{11}=6 \mathrm{kbar}$ during an anneal at $540^{\circ} \mathrm{C}$ for $76 \mathrm{~min}$. is shown in Fig. 2(a). The tensile side (dashed curve) grew faster and the compressive side (solid curve) of this wafer grew slower than did either side of two "control samples" (circles and triangles), which were annealed at low stress on separate runs in the same loading configuration as the high stress samples. The load on the control samples was not reduced all the way to zero, in order to maintain the same thermal contact between wafer and silica rods as in the high-stress sample. Note that the "control samples", unlike the "calibration samples", lie in the same place as the high-stress samples. The growth rates on the tensile and compressive sides approach each other as $x= \pm 10 \mathrm{~mm}$, where the stress vanishes, is approached. In Figs. 2 (b) and (c) we show similar results for different wafers stressed to $6 \mathrm{kbar}$ for $70 \mathrm{~min}$ and $5 \mathrm{kar}$ for $60 \mathrm{~min}$ respectively, at $540^{\circ} \mathrm{C}$. In all cases, the difference between the growth rates on the tensile and compressive sides is maximum in the center of the wafer, where the stress difference is maximum.

Fig. 2. Variation of average solid phase epitaxial growth rate at $540 \mathrm{C}$ with stress along length of bent wafer. Dashed line: tensile side of specimen solid line: compressive side. In each case he magnitude of $\sigma_{11}$, indicated in the figure, is maximaries linearly to zero ot the ends $(x= \pm 10 \mathrm{~mm})$ at the ends $(x= \pm 10 \mathrm{~mm})$ taken from "control" samples under minimal load. Circles correspond to growth on opposite sides of one control sample; triangles to opposite sides of another. Differences berween tensile and compressive sides of high stress samples are greatest in the center, where the stress difference is maximum, and lowest towards the ends, where stresses vanish.

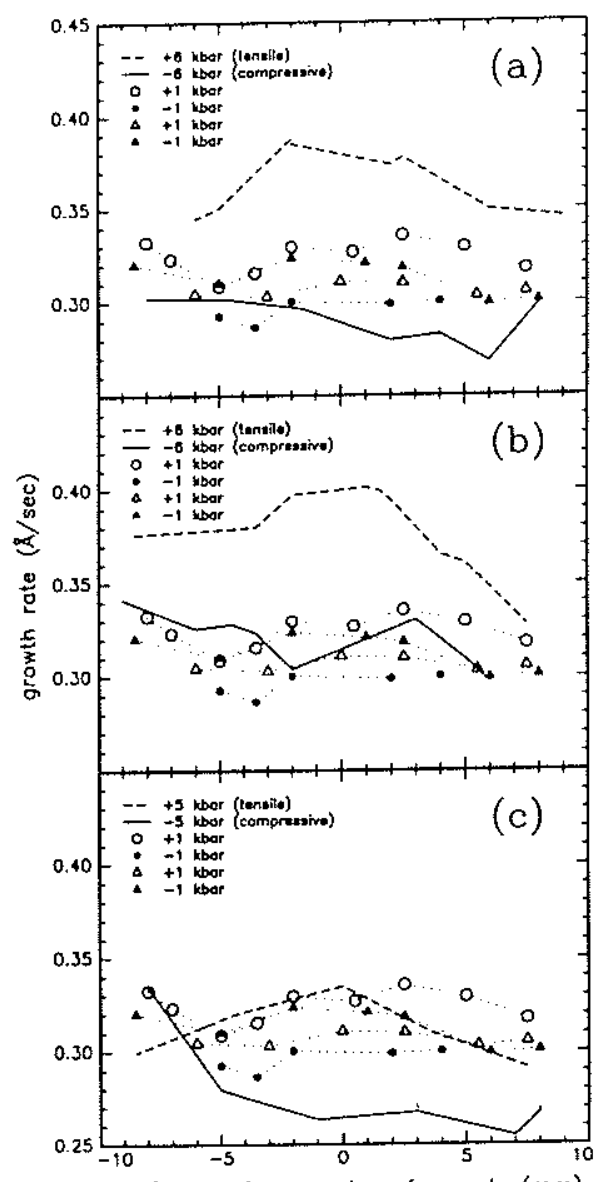

$x$, distance from center of somple (mm)

\section{DISCUSSION}

The failure of the growth rates on the tensile and compressive sides to surround symmetrically the growth rates in the control samples is probably due to a small sample-tosample variation in anneal temperature. However, the temperature difference between two sides of any particular wafer cannot be large enough to account for the difference in growth rates. The vertical temperature gradient in the 9-mm-high chamber was estimated to be no more than 
$0.7^{\circ} \mathrm{C} / \mathrm{mm}$ by two methods. The first, which yielded a gradient of $0.3^{\circ} \mathrm{C} / \mathrm{mm}$, was by moving the thermocouple vertically through the chamber. The second, which yielded a gradient of $0.7^{\circ} \mathrm{C} / \mathrm{mm}$, was by measuring the simultaneous growth rate in the unstressed calibration sample lying at the bottom of the chamber in Fig. 1 and comparing to the average growth rate in the lying at the bottom of the chamber in Fin. I and comparing to the average growth rate in the stressed sample. A calculation of the temperature gradient in the Si waf laking into account

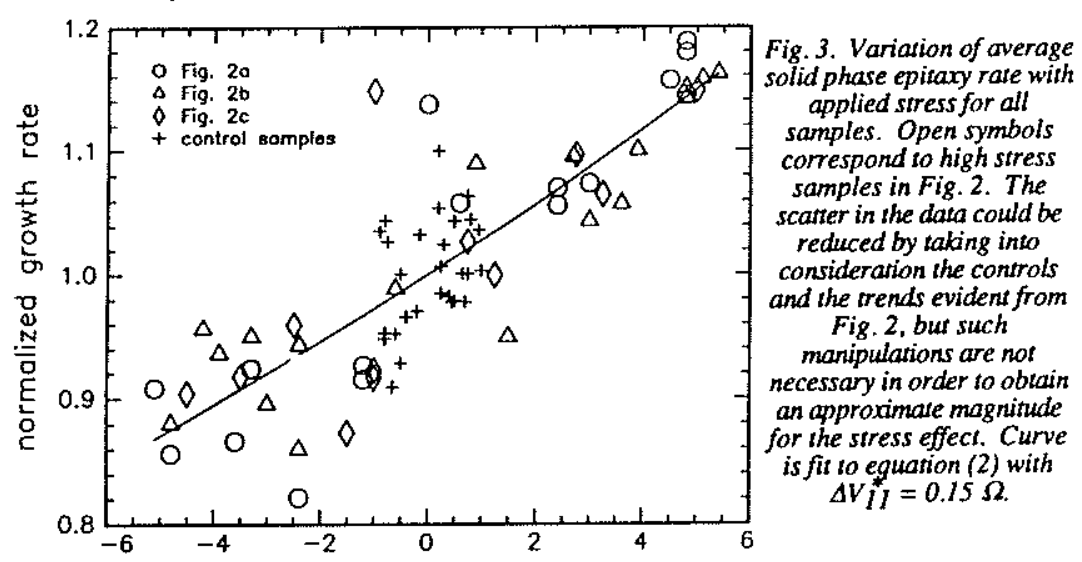

$\sigma_{11}$ (kbor)

through both the silicon wafer and the surrounding air, indicates that the temperature difference through both the silican wa the sample is less than $0.2^{\circ} \mathrm{C}$. (The gradient is between the not large en $5^{\circ} \mathrm{C}$ (hat $5 \mathrm{kbr}$ C for he $5 \mathrm{kbar}$ sample. It is also possible tha the side, and thicker on the compressive side, by flow. The observed effect is over three times too large to be due to flow alone, even with sufficient flow to completely relax all stresses in the a-si.

All data from Fig. 2 are divided by the best-fit zero-stress velocity for each sample, and plotted in Fig. 3 to display the effect of applied stress on the velocity. The curve fit to the data is derived from an extension of transition-state theory (TST) to nonhydrostatic stress states $[9,18]$

In TST, the probability of a fluctuation on the atomic scale from an initial configuration to a
(ndle-point in configuration-space (the "transition state") is evaluated. Stresses (hydrostatic or otherwise) applied to the surfaces of the wafer interact elastically with the fluctuating atomic configurations, biasing the fluctuation probabilities. In solid phase epitaxy, the velocity $v$ is proportional to the probability of fluctuating to the saddle point. TST gives familiar results for the activation energy $\Delta \mathrm{E}^{*}=-\mathrm{k} \partial(\ln v) /\left.\partial(1 / \mathrm{T})\right|_{\mathrm{p}=0}$ and volume $\Delta \mathrm{V}^{*}=-\mathrm{kT} \partial(\ln v) /\left.\partial \mathrm{P}\right|_{\mathrm{T}}$.

Its extension to nonhydrostatic conditions yields $k T \partial(\ln v) / \partial \sigma_{i j}=\Delta \mathrm{V}_{\mathrm{ij}}^{*}$, or

$$
v\left(\sigma_{i j}\right)=v(0) \exp \frac{\sigma_{i j}^{\text {appl }} \Delta V_{i j}^{*}}{k T},
$$

where $\Delta V_{i j}^{*} \equiv V^{*} \bar{\varepsilon}_{i j}^{*}, V^{*}$ is the initial volume of a volume element (the "subsystem") that surrounds the fluctuating atoms and encloses enough material so that all elastic behavior outside the volume element is linear, and $\varepsilon_{i j}^{*}$ is the subsystem-volume-averaged value of $\varepsilon_{\mathrm{ij}}^{*}$, the activation strain tensor, which takes the initial configuration into the saddle point.

When the curve in Fig. 3 is fit to equation (2) we find $\Delta V_{11}^{*}=(0.15 \pm 0.01) \Omega$, where $\Omega$ is the atomic volume of $c-S i$. Since symmetry requires that $\varepsilon_{22}^{*}=\varepsilon_{11}^{*}$ (these are the two in-plane directions), and since we have previously measured [12] the activation volume to be $\Delta V^{*}=-$
$0.28 \Omega$, which corresponds to the trace of $\Delta \mathrm{V}_{\mathrm{ij}}^{*}$, we have $\Delta \mathrm{V}_{33}^{*} / \Omega=-0.58$. Hence the transition state is "short and fat". That is, the fluctuation to the transition state involves an expansion in the two in-plane directions, coupled with a contraction in the direction normal to the surface large two in-plane direction enough to make the overalo is also enhanced by state is enhanced by tension in either of the in-plane directions but is also enhistced by hydrostatic pressure. In our interpretation based on "he mst plausicle atomistic mechanism solid phase epitaxy [15] (the "interface dangling bond" mechanism of Spaepen and Tumbul [19]) the measured activation strain tensor would be the sum of a tensor describing dangling bond formation at the crystal/amorphous interface and a tensor describing dangling bond motion at the interface. We cannot separate the individual contributions of these two tensors from this experiment. However, the model's prediction of a negative volume of motion [20] is very encouraging.

From equation (1), we predict that (i) biaxial stress of the type normally encountered in heteroepitaxy will have the effect of uniaxial stress, squared; (ii) uniaxial compression in the direction normal to the surface will enhance the growth rate even more than does hydrostatic pressure. This explains the excessive magninude of the apparent $\Delta V^{*}$ measured in a pistoncylinder high-pressure apparatus, in which a nonhydrostatic component of just this type might be expected in an early experiment [16].

A measurement of $\Delta V_{\text {for }}$ any kinetic process provides a valuable constraint on proposed A measurement of $\Delta \mathrm{V}_{\mathrm{ij}}$ for any kinetic process provides a valuabe results to rule out bulk poin defect mechanisms for solid phase epitaxy [15].

Thect mechanisms for solid phase epitaxy [1S].

These measurements, though made on a homoepitaxial process, are relevant to

heteroepitaxy. They indicate that if solid phase epitaxy were performed under biaxial tensile stress, for example under conditions of coherence with a substrate with a larger lattice parameter, the stress effect would enhance the rate (although chemical effects might also play a role and the
relative contributions of these and other effects would have to be sorted out). Conversely, in solid phase epitaxy performed under compressive biaxial stress, the stress would tend to retard the rate. This conclusion is consistent with that drawn by Paine et al. [21] in this explain the retardation of solid phase epitaxy rate of strained Si-Ge alloys on $\mathrm{Si}$.

The effect that we have observed is small, but the maximum stress that we could at without shattering the wafer $6 \mathrm{kbar}, 0.6 \mathrm{C}$ ) was als heteroepitaxy, several tens of kilobars can be attained. Combussed above, significantly larger effects might be observed in strained-layer heteroepitaxy.

effects might be observed in strained-layer heteroepitaxy. Although the atomistic mechanism might be different, the same "activation strain" form
is valid for vapor phase epitaxy. Measurements of the activation strain tensor might place is valid for vapor phase epitaxy. Measurements of the activation strain tensor might place constraints on proposed atornistic mechanisms. We expect that the transition state for this process may interact elastically with the surroundings through wafer bending, lattice mism
and surface stresses. Furthermore, an adsorbate might catalyze crystal growth elastically and surface stresses. Furthermore, an adsorbate might catalyze crystal growth elastically opportunities for finding new pathways to low-temperature epitaxial growth.

\section{SUMMARY}

We have measured the effect of uniaxial stress on the kinetics of crystal growth. Solid phase epitaxy is enhanced by uniaxial tension but is also enhanced by hydrostatic compression. The resuls are interpreted in terms of an extension of transition state theory to nonhydrostatic stress rits. The states. The explanaton is that he probs on compression and fat activation strain tensor would be cnhe activation strain tensor provides a means of testing normal to the surface. A measurement of the activation strain tensor provides a means of lesting proposed atomistic mechanisms; we have used this to nule out a class of proposed mech of solid phase epitaxy. Vapor phase epitaxy is one example of the array of other kinetic
processes involving stressed solids for which the activation strain formalism should apply. 


\section{ACKNOWLEDGEMENTS}

We are grateful to K.-R. Lee and J.F. Chervinsky for technical assistance with RBS, to A. Witvrouw for performing curvature measurements, and to J.R. Rice, F. Spaepen, H.A. Stone, and J.A. Golovchenko for helpful discussions. Samples were implanted at the Surface Modification and Characterization Facility at Oak Ridge National Laboratory. This research was supported by NSF-DMR-89-13268. One of us (P.C.S.) was supported jointly by the Undergraduate Faculty Aide Program, the Materials Research Laboratory (NSF-DMR-8920490), and the Division of Applied Sciences at Harvard University.

\section{REFERENCES}

a) Present address: Alcoa Technical Center, 7th Street Road, Route 780, Alcoa Center, PA 15069.

[1] J.Y. Tsao, B.W. Dodson, S.T. Picraux and D.M. Comelison, Phys. Rev. Lett. 52, 2455 (1987)

2] J.W. Matthews and A.E. Blakeslee, J. Cryst. Growth 27, 118 (1974).

3] B.T. Chitton, B.J. Robinson, D.A. Thompson, T.E. Jackman, and J.-M. Baribeau, Appl. Phys. Lelt. \$4, 42 (1989).

[4] F.C. Larche and J.W. Cahn, Acta Metall. 33, 331 (1985)

[5] P.W. Voorhees and W.C. Johnson, J. Chem. Phys. 84, 5108 (1986).

[6] P.W. Voorhees and W.C. Johnson, Phys. Rev. Lett. 61. 225 (1988).

7] P.H. Leo, W.W. Mullins, R.F. Sekerka, and J. Viñals, Acta Metall. Mater. 38, 1573 (1990).

(8) V.J. Fratello, J.F. Hays, and D. Tumbull, J. Appl. Phys. 51, 4718 (1980).

(9] M.J. Aziz, E. Nygren, J.F. Hays and D. Tumbull, J. Appl. Phys. 57, 2233 (1985).

[10] G. Devaud, M.J. Aziz, and D. Tumbull, J. Non-Cryst. Sol. 109, 121 (1989).

(11) E. Chason and M.J. Aziz, submitted to J. Non-Cryst. Sol.

[12] G.Q. Lu, E. Nygren, M.J. Aziz, D. Turnbull and C.W. White, Appl. Phys. Lett. 54 , $2583(1989)$.

[13] G.Q. Lu, E. Nygren, M.J. Aziz, D. Tumbull and C.W. White, Appl. Phys. Lett. 56, 137 (1990).

[14] M.J. Aziz, P.C. Sabin, and G.-Q. Lu, submitted to Phys. Rev. Lett.

15] G.-Q. Lu, E. Nygren, and M.J. Aziz, Mat. Res. Soc. Symp. Proc. 205 (in press, 1991).

[16] E. Nygren, M.J. Aziz, D. Turnbull, J.M. Poate, D.C. Jacobson, and R.Hull, Appl.

[17] A. Witvrouw and F. Spaepen, Mat. Res. Soc. Symp. Proc. 205 (in press, 1991)

[19] Spaepen and Tumbull, AIP Conf. Proc. 50,73 (1979)

[20] V.J. Fratello, J.F. Hays, F. Spaepen, and D. Tumbull, J. Appl. Phys. 51,6160 (1980)

21] D.C. Paine, D.H. Howard, N.Evans, D.J. Greve, M. Racanelli, and N.G. Stoffel, Mat. Res. Soc. Symp. Proc. 202 (in press, 1991).

[22] R.D. Meade and D. Vanderbilt, Phys. Rev. Lett. 63, 1404 (1989).

[23] R.E. Martinez, W.M. Auguştyniak, and J.A. Golovchenko, Phys. Rev. Lett. 64, 1035 (1990). 